\title{
High Speed Solution of Spacecraft Trajectory Problems Using Taylor Series Integration
}

James R. Scott

Glenn Research Center, Cleveland, Ohio

Michael C. Martini

Analex Corporation, Cleveland, Ohio 


\section{NASA STI Program . . . in Profile}

Since its founding, NASA has been dedicated to the advancement of aeronautics and space science. The NASA Scientific and Technical Information (STI) program plays a key part in helping NASA maintain this important role.

The NASA STI Program operates under the auspices of the Agency Chief Information Officer. It collects, organizes, provides for archiving, and disseminates NASA's STI. The NASA STI program provides access to the NASA Aeronautics and Space Database and its public interface, the NASA Technical Reports Server, thus providing one of the largest collections of aeronautical and space science STI in the world. Results are published in both non-NASA channels and by NASA in the NASA STI Report Series, which includes the following report types:

- TECHNICAL PUBLICATION. Reports of completed research or a major significant phase of research that present the results of NASA programs and include extensive data or theoretical analysis. Includes compilations of significant scientific and technical data and information deemed to be of continuing reference value. NASA counterpart of peer-reviewed formal professional papers but has less stringent limitations on manuscript length and extent of graphic presentations.

- TECHNICAL MEMORANDUM. Scientific and technical findings that are preliminary or of specialized interest, e.g., quick release reports, working papers, and bibliographies that contain minimal annotation. Does not contain extensive analysis.

- CONTRACTOR REPORT. Scientific and technical findings by NASA-sponsored contractors and grantees.

- CONFERENCE PUBLICATION. Collected papers from scientific and technical conferences, symposia, seminars, or other meetings sponsored or cosponsored by NASA.

- SPECIAL PUBLICATION. Scientific, technical, or historical information from NASA programs, projects, and missions, often concerned with subjects having substantial public interest.

- TECHNICAL TRANSLATION. Englishlanguage translations of foreign scientific and technical material pertinent to NASA's mission.

Specialized services also include creating custom thesauri, building customized databases, organizing and publishing research results.

For more information about the NASA STI program, see the following:

- Access the NASA STI program home page at http://www.sti.nasa.gov

- E-mail your question via the Internet to help@ sti.nasa.gov

- Fax your question to the NASA STI Help Desk at 301-621-0134

- Telephone the NASA STI Help Desk at 301-621-0390

- Write to: NASA Center for AeroSpace Information (CASI) 7115 Standard Drive Hanover, MD 21076-1320 


\section{High Speed Solution of Spacecraft Trajectory Problems Using Taylor Series Integration}

James R. Scott

Glenn Research Center, Cleveland, Ohio

Michael C. Martini

Analex Corporation, Cleveland, Ohio

Prepared for the

Astrodynamics Specialist Conference and Exhibit

sponsored by the American Institute of Aeronautics and Astronautics and the American Astronautical Society

Honolulu, Hawaii, August 18-21, 2008

National Aeronautics and

Space Administration

Glenn Research Center

Cleveland, Ohio 44135 


\section{Acknowledgments}

The authors would like to thank Glen Horvat and Kurt Hack for their support of this work.

This report is a preprint of a paper intended for presentation at a conference.

Because changes may be made before formal publication, this preprint is made available with the understanding that it will not be cited or reproduced without the permission of the author.

Level of Review: This material has been technically reviewed by technical management.

Available from

NASA Center for Aerospace Information 7115 Standard Drive

Hanover, MD 21076-1320
National Technical Information Service 5285 Port Royal Road Springfield, VA 22161 


\title{
High Speed Solution of Spacecraft Trajectory Problems Using Taylor Series Integration
}

\author{
James R. Scott \\ National Aeronautics and Space Administration \\ Glenn Research Center \\ Cleveland, Ohio 44135 \\ Michael C. Martini \\ Analex Corporation \\ Cleveland, Ohio 44135
}

Taylor series integration is implemented in a spacecraft trajectory analysis code - the Spacecraft N-body Analysis Program (SNAP) - and compared with the code's existing eighth-order Runge-Kutta Fehlberg time integration scheme. Nine trajectory problems, including near Earth, lunar, Mars and Europa missions, are analyzed. Head-to-head comparison at five different error tolerances shows that, on average, Taylor series is faster than Runge-Kutta Fehlberg by a factor of 15.8. Results further show that Taylor series has superior convergence properties. Taylor series integration proves that it can provide rapid, highly accurate solutions to spacecraft trajectory problems.

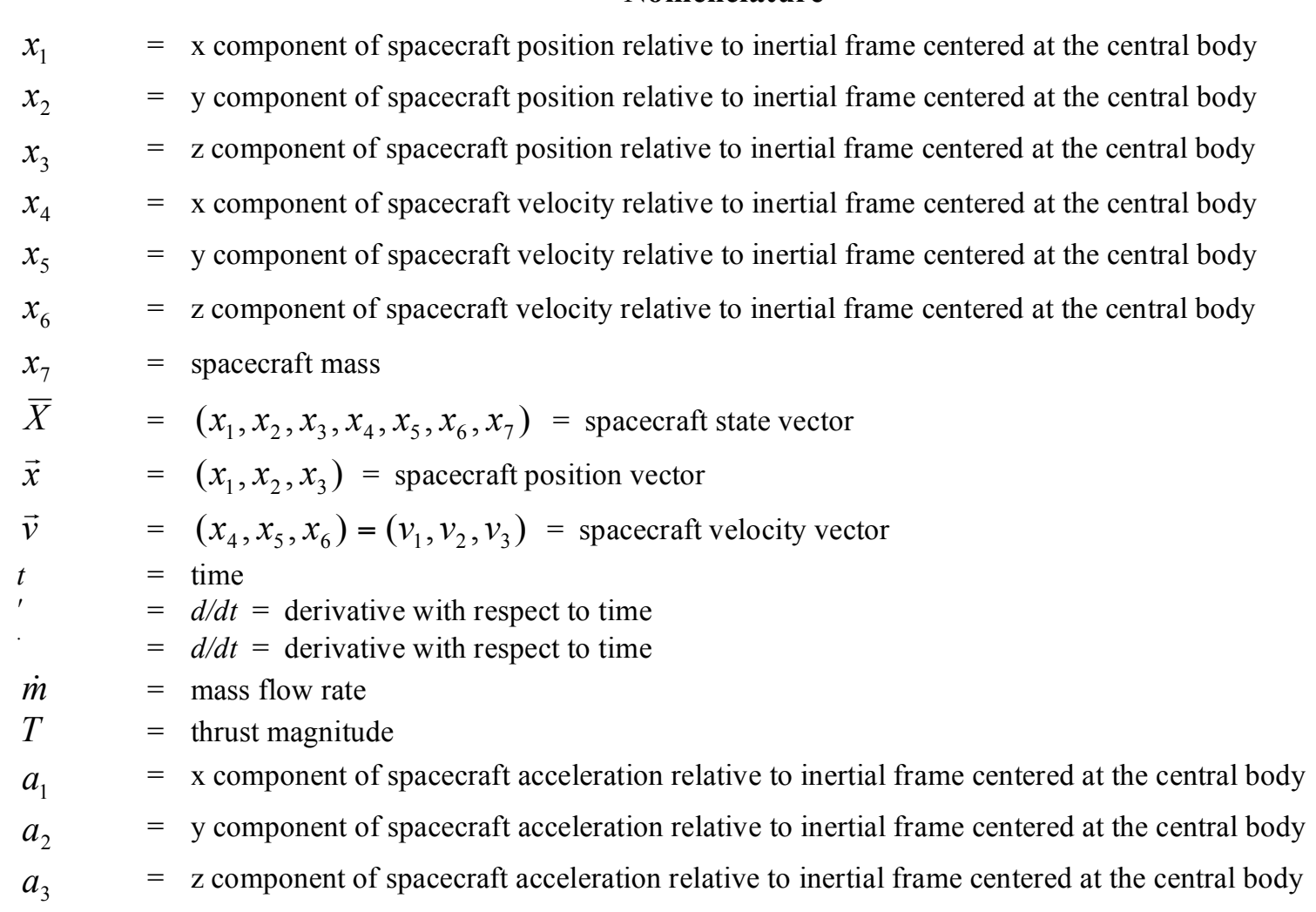




$\begin{array}{ll}\vec{a} & =\left(a_{1}, a_{2}, a_{3}\right)=\text { acceleration vector } \\ \vec{x}_{j} & =\text { position vector of the } j^{\text {th }} \text { other body relative to the central body } \\ G & =\text { gravitational constant } \\ M & =\text { body mass } \\ h & =\text { step size } \\ \tau & =\text { local error tolerance } \\ \eta & =\text { step multiplication factor }\end{array}$

\section{Introduction}

$\mathrm{T}$

he advantages of Taylor series integration in solving ordinary differential equations have been known for some time ${ }^{1-25}$. Foremost among these is the ability to maintain very high computational efficiency while achieving high accuracy. In fact, comparisons with other methods have shown that Taylor series integration can be faster by a factor of twenty or more ${ }^{20}$.

The success of the method depends on recasting the governing differential system into a canonical form whereby system derivatives can be obtained to arbitrary order through recursion. This obviates the need to directly calculate derivatives, and makes it possible to obtain derivative information cheaply. The system variables can thus be expanded in a highly accurate series at each time level at minimal cost.

It turns out that most differential systems can be recast into the required canonical form in a straightforward manner. This has led a number of authors to develop general purpose software which can recast an arbitrary system into canonical form and solve the resulting equations automatically ${ }^{10,11,15-18,22-24}$. Taylor series integration can thus be used as both a general purpose solver and also for specific applications.

The focus here is on calculating spacecraft trajectories. Previous work using Taylor series to calculate trajectories includes that in Refs. 21 and 22. Unlike Refs. 21 and 22, which used an automated Taylor series package ${ }^{16,22}$ to propagate trajectories in Earth orbit, the present work focuses on using Taylor series integration in an existing trajectory analysis code, SNAP (Spacecraft N-body Analysis Program) ${ }^{26}$. Developed at NASA's Glenn Research Center, SNAP is a high fidelity trajectory propagation program that can propagate the trajectory of a spacecraft about virtually any body in the solar system. The equations of motion include the effects of central body gravitation with $\mathrm{N} \times \mathrm{N}$ harmonics, other body gravitation with $\mathrm{N} \times \mathrm{N}$ harmonics, solar radiation pressure, atmospheric drag (for Earth orbits) and spacecraft thrusting (including shadowing). The equations are solved using an eighth-order Runge-Kutta Fehlberg (RKF) ${ }^{27}$ single step method with variable step size control.

The purpose of this paper is to demonstrate the use of Taylor series (TS) integration in a high fidelity trajectory analysis code, SNAP, and to provide a detailed comparison of TS performance to eighth-order RKF ${ }^{27}$. Section II presents the equations of motion, Section III describes the TS formulation and Section IV discusses the numerical implementation. Section V compares TS and RKF on a representative set of spacecraft trajectory problems, including near Earth, lunar, Mars and Europa missions. It is shown that TS is faster than RKF by an average factor of 15.8, while simultaneously improving accuracy.

\section{Equations of Motion}

Let $\bar{X}=\left(x_{1}, x_{2}, x_{3}, x_{4}, x_{5}, x_{6}, x_{7}\right)$ denote the spacecraft state vector, where $\left(x_{1}, x_{2}, x_{3}\right)=\vec{x}$ is the spacecraft position in Cartesian coordinates relative to an inertial frame centered at the central body, $\left(x_{4}, x_{5}, x_{6}\right)=\vec{v}$ is the spacecraft velocity relative to an inertial frame centered at the central body, and $x_{7}$ is the spacecraft mass. The equations of motion are

$$
\begin{aligned}
& x_{1}^{\prime}=x_{4} \\
& x_{2}^{\prime}=x_{5} \\
& x_{3}^{\prime}=x_{6}
\end{aligned}
$$




$$
\begin{aligned}
& x_{4}^{\prime}=a_{1}\left(x_{1}, x_{2}, x_{3}, x_{4}, x_{5}, x_{6}, x_{7}, t\right) \\
& x_{5}^{\prime}=a_{2}\left(x_{1}, x_{2}, x_{3}, x_{4}, x_{5}, x_{6}, x_{7}, t\right) \\
& x_{6}^{\prime}=a_{3}\left(x_{1}, x_{2}, x_{3}, x_{4}, x_{5}, x_{6}, x_{7}, t\right) \\
& x_{7}^{\prime}=-\dot{m}(t)
\end{aligned}
$$

where $a_{i}$ is the acceleration in the $i^{\text {th }}$ coordinate direction and $\dot{m}$ is the mass flow rate. The acceleration is a function of the forces acting on the spacecraft. Forces included in SNAP are central body, other body, thrust, atmospheric drag (for low Earth orbits), solar radiation pressure, oblateness effects of Earth, and oblateness effects of other bodies, so that

$$
\vec{a}=\vec{a}_{c b}+\vec{a}_{o b}+\vec{a}_{t h}+\vec{a}_{d}+\vec{a}_{s r p}+\vec{a}_{o b e}+\vec{a}_{o b o}
$$

This paper considers only the first four acceleration terms, which are given below.

$$
a_{c b, i}=-G M_{c b} \frac{x_{i}}{\left(x_{1}^{2}+x_{2}^{2}+x_{3}^{2}\right)^{\frac{3}{2}}} \quad:=-G M_{c b} \frac{x_{i}}{|\vec{x}|^{3}}
$$

where $G$ is the gravitational constant, $M_{c b}$ is the central body mass, $i=1,2,3$ denotes the coordinate direction, and the spacecraft mass is much less than the central body mass.

$$
a_{o b, i}=\sum_{j}-G M_{j}\left(\frac{x_{i}-x_{i, j}}{\left|\vec{x}-\vec{x}_{j}\right|^{3}}+\frac{x_{i, j}}{\left|\vec{x}_{j}\right|^{3}}\right)
$$

where $j$ denotes the $j^{\text {th }}$ body and $\left|\vec{x}_{j}\right|:=\left(x_{1, j}^{2}+x_{2, j}^{2}+x_{3, j}^{2}\right)^{\frac{1}{2}}$.

$$
a_{t h, i}=T \frac{v_{i}}{|\vec{v}|} \frac{1}{x_{7}}
$$

where $T$ is the constant thrust magnitude and the thrust direction is parallel to the velocity vector.

$$
\begin{gathered}
a_{d, 1}=c_{1}\left[\left(x_{4}+c_{2} x_{2}\right)^{2}+\left(x_{5}-c_{2} x_{1}\right)^{2}+x_{6}^{2}\right]^{\frac{1}{2}}\left(x_{4}+c_{2} x_{2}\right) / x_{7} \\
a_{d, 2}=c_{1}\left[\left(x_{4}+c_{2} x_{2}\right)^{2}+\left(x_{5}-c_{2} x_{1}\right)^{2}+x_{6}^{2}\right]^{\frac{1}{2}}\left(x_{5}-c_{2} x_{1}\right) / x_{7} \\
a_{d, 3}=c_{1}\left[\left(x_{4}+c_{2} x_{2}\right)^{2}+\left(x_{5}-c_{2} x_{1}\right)^{2}+x_{6}^{2}\right]^{\frac{1}{2}} x_{6} / x_{7}
\end{gathered}
$$

where $c_{1}=-\frac{1}{2} C_{D} \cdot($ spacecraft area $) \cdot($ atmospheric density $), c_{2}=$ rotation rate of Earth and $C_{D}$ is the drag coefficient. 


\section{Taylor Series Formulation}

Let the state vector $\bar{X}$ have initial condition $\bar{X}_{0}$. Within the radius of convergence, the system variables $x_{n}(t)$ can be expanded in a Taylor series,

$$
x_{n}(t)=\sum_{k=0}^{\infty} \frac{x_{n}^{(k)}\left(t_{0}\right)}{k !}\left(t-t_{0}\right)^{k}, \quad n=1, \ldots, 7
$$

where the derivatives $x_{n}^{(k)}$ are obtained by successively differentiating the right hand side of Eqs. (1). This can be efficiently accomplished using recurrence relations, as follows. Consider only the central body acceleration term, so that

$$
\begin{gathered}
x_{1}^{\prime}=x_{4} \\
x_{2}^{\prime}=x_{5} \\
x_{3}^{\prime}=x_{6} \\
x_{4}^{\prime}=-G M_{c b} \frac{x_{1}}{\left(x_{1}^{2}+x_{2}^{2}+x_{3}^{2}\right)^{\frac{3}{2}}} \\
x_{5}^{\prime}=-G M_{c b} \frac{x_{2}}{\left(x_{1}^{2}+x_{2}^{2}+x_{3}^{2}\right)^{\frac{3}{2}}} \\
x_{6}^{\prime}=-G M_{c b} \frac{x_{3}}{\left(x_{1}^{2}+x_{2}^{2}+x_{3}^{2}\right)^{\frac{3}{2}}} \\
x_{7}^{\prime}=0
\end{gathered}
$$

Introduce $x_{8}$ and $x_{9}$,

$$
\begin{gathered}
x_{8}=x_{1}^{2}+x_{2}^{2}+x_{3}^{2} \\
x_{9}=x_{8}^{3 / 2}
\end{gathered}
$$

Eqs. (10) become

$$
\begin{gathered}
x_{1}^{\prime}=x_{4} \\
x_{2}^{\prime}=x_{5} \\
x_{3}^{\prime}=x_{6} \\
x_{4}^{\prime}=-G M_{c b} \frac{x_{1}}{x_{9}} \\
x_{5}^{\prime}=-G M_{c b} \frac{x_{2}}{x_{9}}
\end{gathered}
$$




$$
\begin{gathered}
x_{6}^{\prime}=-G M_{c b} \frac{x_{3}}{x_{9}} \\
x_{7}^{\prime}=0
\end{gathered}
$$

and two auxiliary equations are added to the system:

$$
\begin{gathered}
x_{8}^{\prime}=2 x_{1} x_{4}+2 x_{2} x_{5}+2 x_{3} x_{6} \\
x_{9}^{\prime}=\frac{3}{2} \frac{x_{9} x_{8}^{\prime}}{x_{8}}
\end{gathered}
$$

The right hand side of the new system, Eqs. (13) - (15), can now be differentiated using recurrence relations for products and quotients.

For a function $w(t)=f(t) g(t)$, the Leibnitz rule for differentiating products gives ${ }^{16}$

$$
W(k)=\sum_{j=0}^{k} F(j) G(k-j)
$$

where $W(k):=\frac{w^{(k)}\left(t_{0}\right)}{k !}, \quad F(j):=\frac{f^{(j)}\left(t_{0}\right)}{j !}$ and $G(k-j):=\frac{g^{(k-j)}\left(t_{0}\right)}{(k-j) !}$ are reduced derivatives.

For a function $w(t)=\frac{f(t)}{g(t)}$, the recurrence relation for quotients gives ${ }^{11}$

$$
W(k)=\frac{1}{g}\left[F(k)-\sum_{j=1}^{k} G(j) W(k-j)\right]
$$

where $W, F$ and $G$ are reduced derivatives as above.

The recurrence relations are derived as follows. Let

$$
u_{n}=x_{n}^{\prime}, \quad n=1, \ldots, 9
$$

Eqs. (13) - (15) become

$$
\begin{gathered}
u_{1}=x_{4} \\
u_{2}=x_{5} \\
u_{3}=x_{6} \\
u_{4}=-G M_{c b} \frac{x_{1}}{x_{9}} \\
u_{5}=-G M_{c b} \frac{x_{2}}{x_{9}}
\end{gathered}
$$




$$
\begin{gathered}
u_{6}=-G M_{c b} \frac{x_{3}}{x_{9}} \\
u_{7}=0 \\
u_{8}=2 x_{1} x_{4}+2 x_{2} x_{5}+2 x_{3} x_{6} \\
u_{9}=\frac{3}{2} \frac{x_{9} u_{8}}{x_{8}}
\end{gathered}
$$

Introduce auxiliary functions $w_{4}=\frac{x_{1}}{x_{9}}, w_{5}=\frac{x_{2}}{x_{9}}, w_{6}=\frac{x_{3}}{x_{9}}, w_{8,1}=x_{1} x_{4}, w_{8,2}=x_{2} x_{5}, w_{8,3}=x_{3} x_{6}$, and $w_{9}=\frac{x_{9} u_{8}}{x_{8}}$.

Using Eq. (18) one obtains

$$
u_{n}^{(k-1)}=x_{n}^{(k)}, \quad k \geq 1
$$

from which

$$
\begin{gathered}
\frac{u_{n}^{(k-1)}}{(k-1) !}=\frac{x_{n}^{(k)}}{(k-1) !}, \quad k \geq 1 \\
\Rightarrow U_{n}(k-1)=k X_{n}(k) \Rightarrow X_{n}(k)=\frac{U_{n}(k-1)}{k}, \quad k \geq 1
\end{gathered}
$$

The recurrence relations are then, for all $k \geq 1$,

$$
\begin{gathered}
U_{1}(k)=X_{4}(k)=\frac{U_{4}(k-1)}{k} \\
U_{2}(k)=X_{5}(k)=\frac{U_{5}(k-1)}{k} \\
U_{3}(k)=X_{6}(k)=\frac{U_{6}(k-1)}{k} \\
U_{4}(k)=-G M_{c b} W_{4}(k) \\
U_{5}(k)=-G M_{c b} W_{5}(k) \\
U_{6}(k)=-G M_{c b} W_{6}(k)
\end{gathered}
$$




$$
\begin{gathered}
U_{7}(k)=0 \\
U_{8}(k)=2 W_{8,1}(k)+2 W_{8,2}(k)+2 W_{8,3}(k) \\
U_{9}(k)=\frac{3}{2} W_{9}(k)
\end{gathered}
$$

where

$$
\begin{gathered}
W_{4}(k)=\frac{1}{x_{9}}\left[X_{1}(k)-\sum_{j=1}^{k} X_{9}(j) W_{4}(k-j)\right]=\frac{1}{x_{9}}\left[\frac{U_{1}(k-1)}{k}-\sum_{j=1}^{k} \frac{U_{9}(j-1)}{j} W_{4}(k-j)\right] \\
W_{8,1}(k)=\sum_{j=0}^{k} X_{1}(j) X_{4}(k-j)=x_{1} \frac{U_{4}(k-1)}{k}+\frac{U_{1}(k-1)}{k} x_{4}+\sum_{j=1}^{k-1} \frac{U_{1}(j-1)}{j} \frac{U_{4}(k-j-1)}{k-j}
\end{gathered}
$$

etc., and a similar expression can be derived for $W_{9}$.

The Taylor series coefficients are then

$$
\frac{x_{n}^{(k)}}{k !}:=X_{n}(k)=\frac{U_{n}(k-1)}{k}, \quad 1 \leq k \leq K
$$

and the local series solution is

$$
x_{n}(t)=\sum_{k=0}^{K} \frac{x_{n}^{(k)}\left(t_{0}\right)}{k !}\left(t-t_{0}\right)^{k}+T_{n, K}
$$

where $U_{n}(k)$ is defined by Eqs. (31) - (39), $U_{n}(0)$ is defined by Eqs. (19) - (27), $K$ is the number of terms in the series and $T_{n, K}$ is the truncation error.

The other acceleration terms can be handled similarly. Only other body acceleration, Eq. (4), requires special consideration, due to the need for the motion of other bodies. This can generally be obtained from ephemeris files. However, integration by Taylor series requires derivatives not available from ephemeris files. It is thus necessary to integrate the other body motion as part of the governing differential system. This leads to a substantially larger system of equations, but fortunately can still be integrated efficiently.

Once the recurrence relations are derived for all acceleration terms and the state vector specified, Eqs. (42) (43) are used to expand the system variables in a series from $t_{0}$ to $t_{1}$, where the step size $h_{1}:=t_{1}-t_{0}$ is determined to meet the local error tolerance. From $t_{1}$, the variables are expanded in a new series to $t_{2}$, and so forth. Thus, by a process of "analytic continuation," one obtains a set of overlapping series solutions that cover the integration domain.

\section{Numerical Implementation}

Taylor series integration was implemented in SNAP by making some minor modifications to existing source code and adding three additional subroutines - a driver routine which automatically introduces auxiliary variables, sets up initial conditions and integrates; a routine which calculates system reduced derivatives using recurrence 
relations for the following quotients and products: $\frac{x_{m}}{x_{n}}, x_{m} x_{n}, \frac{x_{m} x_{n}^{\prime}}{x_{n}}, x_{m} x_{m}^{\prime}, \frac{x_{m}^{\prime}}{x_{n}}, \frac{x_{m} x_{n}}{x_{l}}$ and $x_{m} x_{n}^{\prime}$; and a routine which determines the step size and sums the series. The number of series terms is variable up to a maximum of 30 , but remains constant throughout the integration. Positive and negative terms are summed separately to avoid cancellation of significant digits.

The step size can be determined from the standard formula ${ }^{28}$

$$
h_{\text {next }}=\eta h\left(\frac{\tau}{e_{\max }}\right)^{\frac{1}{M}}
$$

where $h$ denotes the current step, $\tau$ the local error tolerance, $e_{\max }$ the estimate of maximum truncation error, $M$ the order of the maximum truncation error estimate and $\eta<1$ the step multiplication factor. Eq. (44) is more or less restrictive depending on $\eta$ and the truncation error estimate $e_{\max }$. Generally, $e_{\max }$ should not be calculated from the next series term, due to the extra computation required and the fact that it is not a reliable error estimate ${ }^{29}$. A conservative approach which takes advantage of the series terms already computed leads to

$$
e_{\max }=\operatorname{Max}_{n}\left[\left|X_{n}(K-1)\right| h^{K-1}+\left|X_{n}(K)\right| h^{K}\right]
$$

where the expression in brackets is derived by subtracting the Taylor series solution of degree $K-2$ from the solution of degree $K$ and taking absolute values of individual terms. Eq. (45) can be viewed as a truncation error estimate for the series of degree $K-2$ which is then applied to the more accurate series of degree $K$.

An alternative to Eqs. (44) - (45) is to simply require $h$ to be small enough that the system variables directly satisfy the absolute error tolerance requirement

$$
\left|X_{n}(K-1)\right| h^{K-1}+\left|X_{n}(K)\right| h^{K} \leq \tau
$$

for all $n$. Eq. (46) can be solved by fixed point iteration,

$$
h_{l+1}=\exp \left(\frac{1}{K-1} \ln \frac{\tau}{\left|X_{n}(K-1)\right|+h_{l}\left|X_{n}(K)\right|}\right)
$$

The smallest $h$ is chosen over all $n$, and multiplied by the step multiplication factor $\eta$. This approach offers the advantage of directly calculating the step size without the need for a previous step, and guarantees that the error tolerance is met. Eq. (44), on the other hand, requires a previous step and will require a repeat step whenever $e_{\max }>\tau$.

The step selection methods above performed very similarly in the current study. Both methods provided stable, accurate solutions and used approximately the same number of time steps in head-to-head calculations.

\section{Results}

We compare RKF and TS performance on the trajectory problems in Table 1. All calculations were run on a Dell PowerEdge 2600 with two $3.066 \mathrm{GHz}$ processors and four GB of RAM. Source code was compiled using the Absoft Fortran 90 compiler without optimization. SNAP was run with all intermediate print and stop options turned off. All TS calculations used a series with 20 terms and a variable step size determined by Eq. (47) with a step multiplication factor that ranged from 0.75 to 0.9 . 
Table 1

\begin{tabular}{|c|c|c|c|c|}
\hline Problem & Title & Description & $\begin{array}{l}\text { Central } \\
\text { Body }\end{array}$ & Other Bodies \\
\hline 1 & $\begin{array}{l}\text { Satellite in low } \\
\text { Earth orbit } \\
(\mathrm{LEO})\end{array}$ & $\begin{array}{l}\text { A } 10,000 \mathrm{~kg} \text { satellite orbits Earth for } 10 \text { days } \\
\text { at an inclination of } 28.45 \text { degrees. }\end{array}$ & Earth & Moon \\
\hline 2 & $\begin{array}{l}\text { Satellite in LEO } \\
\text { with drag }\end{array}$ & $\begin{array}{l}\text { A } 10,000 \mathrm{~kg} \text { satellite orbits Earth for } 10 \text { days } \\
\text { with constant drag at an inclination of } 28.45 \\
\text { degrees. }\end{array}$ & Earth & Moon \\
\hline 3 & $\begin{array}{l}\text { Spacecraft } \\
\text { spiraling out of } \\
\text { Earth's gravity } \\
\text { well }\end{array}$ & $\begin{array}{l}\text { A } 10,000 \mathrm{~kg} \text { spacecraft spirals out of Earth's } \\
\text { gravity well in a low thrust trajectory. } \\
\text { Calculation stops when the semi-major axis } \\
\text { of trajectory equals } 40,000 \mathrm{~km} \text {. }\end{array}$ & Earth & Sun, Moon \\
\hline 4 & $\begin{array}{l}\text { Spacecraft from } \\
\text { near Earth to } \\
\text { lunar orbit }\end{array}$ & $\begin{array}{l}\text { A } 3580 \mathrm{~kg} \text { spacecraft } 400 \mathrm{~km} \text { above Earth has } \\
\text { been propelled with sufficient energy to reach } \\
\text { the Moon. Spacecraft coasts to Moon, } \\
\text { performs insertion burn, propagates to } \\
\text { apolune, and performs final burn to achieve } \\
500 \mathrm{~km} \text { by } 10,000 \mathrm{~km} \text { polar lunar orbit with } \\
\text { an argument of perilune equal to } 90 \text { degrees. } \\
\text { See Fig. } 1 \text {. }\end{array}$ & Moon & Earth, Sun \\
\hline 5 & $\begin{array}{l}\text { Spacecraft in } \\
\text { lunar orbit }\end{array}$ & $\begin{array}{l}\text { Spacecraft with } 2848.56 \mathrm{~kg} \text { mass coasts for } \\
10 \text { days in } 500 \mathrm{~km} \text { by } 10,000 \mathrm{~km} \text { polar lunar } \\
\text { orbit with an argument of perilune equal to } 90 \\
\text { degrees. See Fig. } 1 \text {. }\end{array}$ & Moon & $\begin{array}{l}\text { Earth, } \\
\text { Sun }\end{array}$ \\
\hline 6 & $\begin{array}{l}\text { Spacecraft } \\
\text { thrusting from } \\
\text { near Earth to } \\
\text { Mars coast } \\
\end{array}$ & $\begin{array}{l}\text { A } 585 \mathrm{~kg} \text { spacecraft near Earth thrusts for } \\
38.45 \text { days to achieve sufficient energy to } \\
\text { coast to Mars. See Fig. } 2 \text {. }\end{array}$ & Sun & $\begin{array}{l}\text { Earth, Moon, Venus, Mars, } \\
\text { Jupiter barycenter, } \\
\text { Saturn barycenter }\end{array}$ \\
\hline 7 & $\begin{array}{l}\text { Spacecraft coast } \\
\text { to Mars flyby }\end{array}$ & $\begin{array}{l}\text { A } 555.66 \mathrm{~kg} \text { spacecraft coasts to Mars flyby } \\
\text { for } 161.55 \text { days. See Fig. } 2 .\end{array}$ & Sun & $\begin{array}{c}\text { Earth, Moon, Venus, Mars, } \\
\text { Jupiter barycenter, } \\
\text { Saturn barycenter }\end{array}$ \\
\hline 8 & $\begin{array}{l}\text { Spacecraft } \\
\text { thrusting } \\
\text { tangentially out } \\
\text { of Europa orbit } \\
\end{array}$ & $\begin{array}{l}\text { A } 10,000 \mathrm{~kg} \text { spacecraft in Europa orbit } \\
\text { thrusts tangentially to spiral out until the } \\
\text { semi-major axis equals } 10,000 \mathrm{~km} \text {. }\end{array}$ & Europa & $\begin{array}{c}\text { Jupiter, Sun, Ganymede, Io } \\
\text { Callisto }\end{array}$ \\
\hline 9 & $\begin{array}{l}\text { Spacecraft coast } \\
\text { near Europa }\end{array}$ & $\begin{array}{l}\text { A } 9800.49 \mathrm{~kg} \text { spacecraft coasts for one day } \\
\text { after spiraling out of Europa orbit. }\end{array}$ & Europa & $\begin{array}{c}\text { Jupiter, Sun, Ganymede, Io } \\
\text { Callisto } \\
\end{array}$ \\
\hline
\end{tabular}



Figure 1. Earth to Moon Trajectory

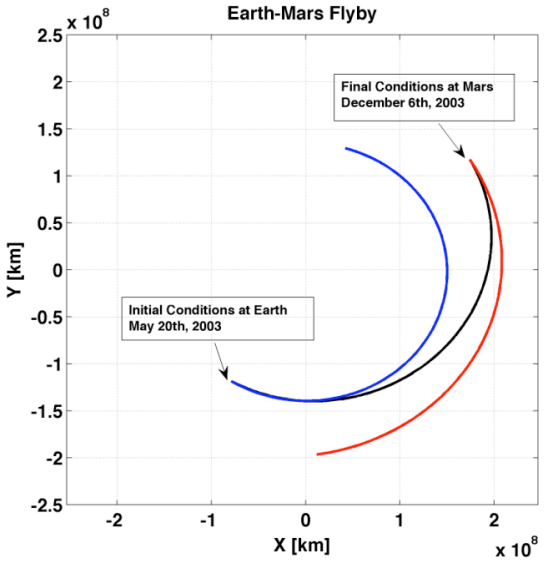

Figure 2. Earth to Mars Flyby 
Each trajectory was integrated at five error tolerances from $10^{-10}$ to $10^{-14}$. Tables $2-10$ summarize the results. RKF results are shown on top and TS on bottom. Spacecraft positions are in kilometers and CPU ratio is RKF/TS. RKF and TS velocities agreed equally well as spacecraft position, but are omitted here for brevity.

Table 2 Results for Problem 1

\begin{tabular}{ccccccc}
\multicolumn{4}{c}{ Spacecraft Position at End of Calculation } & CPU & CPU \\
$\tau$ & $\mathrm{x}$ & $\mathrm{y}$ & $\mathrm{z}$ & $(\mathrm{sec})$ & ratio \\
1.E-10 & -4505.4956174253 & 4460.8015923075 & 2416.2243468200 & 6.91 & \\
1.E-11 & -4505.4976241104 & 4460.8000212437 & 2416.2234952381 & 9.10 & \\
1.E-12 & -4505.4977855238 & 4460.7998948715 & 2416.2234267390 & 12.23 & \\
1.E-13 & -4505.4977981582 & 4460.7998849798 & 2416.2234213773 & 16.05 & \\
1.E-14 & -4505.4977991371 & 4460.7998842135 & 2416.2234209620 & 21.17 & \\
& & & & & & \\
1.E-10 & -4505.4893402433 & 4460.8066582279 & 2416.2273550484 & 0.20 & 34.6 \\
1.E-11 & -4505.4893401709 & 4460.8066582847 & 2416.2273550792 & 0.22 & 41.4 \\
1.E-12 & -4505.4893402598 & 4460.8066582151 & 2416.2273550415 & 0.25 & 48.9 \\
1.E-13 & -4505.4893403875 & 4460.8066581153 & 2416.2273549873 & 0.28 & 57.3 \\
1.E-14 & -4505.4893402869 & 4460.8066581940 & 2416.2273550300 & 0.31 & 68.3
\end{tabular}

Table 3 Results for Problem 2

Spacecraft Position at End of Calculation $\quad$ CPU CPU

$\begin{array}{cccccc}\tau & \mathrm{x} & \mathrm{y} & \mathrm{z} & (\mathrm{sec}) & \text { ratio } \\ . \mathrm{E}-10 & -6286.5348347365 & 2234.8075149479 & 1209.8215168263 & 7.04 & \\ . \mathrm{E}-11 & -6286.5358380683 & 2234.8053241518 & 1209.8203296255 & 9.16 & \\ . \mathrm{E}-12 & -6286.5359189241 & 2234.8051476038 & 1209.8202339534 & 12.18 & \\ . \mathrm{E}-13 & -6286.5359251975 & 2234.8051339059 & 1209.8202265305 & 16.04 & \\ \text {.E-14 } & -6286.5359257481 & 2234.8051327038 & 1209.8202258791 & 21.28 & \\ & & & & & \\ \text { E-10 } & -6286.5317837499 & 2234.8146866042 & 1209.8256504332 & 0.26 & 27.1 \\ . \mathrm{E}-11 & -6286.5317836592 & 2234.8146868021 & 1209.8256505404 & 0.29 & 31.6 \\ . \mathrm{E}-12 & -6286.5317837023 & 2234.8146867081 & 1209.8256504895 & 0.33 & 36.9 \\ . \mathrm{E}-13 & -6286.5317837303 & 2234.8146866471 & 1209.8256504564 & 0.37 & 43.4 \\ . \mathrm{E}-14 & -6286.5317836427 & 2234.8146868382 & 1209.8256505600 & 0.42 & 50.7\end{array}$

Table 4 Results for Problem 3

\begin{tabular}{ccccccc}
\multicolumn{4}{c}{ Spacecraft Position at End of Calculation } & CPU & CPU \\
1.E-10 & 21783.589218926 & 30426.566335107 & 14117.151742798 & 44.01 & \\
1.E-11 & 21783.168251826 & 30426.814392403 & 14117.266771932 & 58.17 & \\
1.E-12 & 21783.134612346 & 30426.834214343 & 14117.275963762 & 77.72 & \\
$1 . E-13$ & 21783.131993250 & 30426.835757635 & 14117.276679417 & 102.06 & \\
1.E-14 & 21783.131799858 & 30426.835871591 & 14117.276732261 & 134.87 & \\
& & & & & & \\
1.E-10 & 21783.126013948 & 30426.839470527 & 14117.277961164 & 2.29 & 19.2 \\
1.E-11 & 21783.126025067 & 30426.839463974 & 14117.277958125 & 2.57 & 22.6 \\
1.E-12 & 21783.126012532 & 30426.839471362 & 14117.277961551 & 2.88 & 27.0 \\
1.E-13 & 21783.126009565 & 30426.839473099 & 14117.277962357 & 3.27 & 31.2 \\
1.E-14 & 21783.126006877 & 30426.839474690 & 14117.277963095 & 3.69 & 36.6
\end{tabular}


Table 5 Results for Problem 4

\begin{tabular}{|c|c|c|c|c|c|}
\hline \multirow[b]{2}{*}{$\tau$} & \multicolumn{3}{|c|}{ Spacecraft Position at End of Calculation } & \multirow{2}{*}{$\begin{array}{l}\text { CPU } \\
(\mathrm{sec})\end{array}$} & \multirow{2}{*}{$\begin{array}{l}\mathrm{CPU} \\
\text { ratio }\end{array}$} \\
\hline & $\mathrm{x}$ & $\mathrm{y}$ & $\mathrm{z}$ & & \\
\hline 1.E-10 & -178.63870529793 & 4876.3161604664 & -10650.392195425 & 0.44 & \\
\hline 1.E-11 & -178.63855098380 & 4876.3170369698 & -10650.391796702 & 0.51 & \\
\hline 1.E-12 & -178.63855046608 & 4876.3170506570 & -10650.391790443 & 0.59 & \\
\hline 1.E-13 & -178.63855601675 & 4876.3170085371 & -10650.391809627 & 0.71 & \\
\hline 1.E-14 & -178.63854695266 & 4876.3170607540 & -10650.391785873 & 0.87 & \\
\hline 1.E-10 & -178.71939471463 & 4876.1033547743 & -10650.488272923 & 0.19 & 1 \\
\hline 1.E-11 & -178.71939481530 & 4876.1033542962 & -10650.488273141 & 0.20 & 5 \\
\hline 1.E-12 & -178.71939478451 & 4876.1033544409 & -10650.488273078 & 0.20 & 2.95 \\
\hline 1.E-13 & -178.71939478450 & 4876.1033544292 & -10650.488273079 & 0.20 & 3.55 \\
\hline 1.E-14 & -178.71939478714 & 4876.1033544962 & -10650.488273051 & 0.20 & 4.35 \\
\hline
\end{tabular}

Table 6 Results for Problem 5

\begin{tabular}{|c|c|c|c|c|c|}
\hline \multicolumn{4}{|c|}{ Spacecraft Position at End of Calculation } & \multirow{2}{*}{$\begin{array}{l}\mathrm{CPU} \\
(\mathrm{sec})\end{array}$} & \multirow{2}{*}{$\begin{array}{l}\mathrm{CPU} \\
\text { ratio }\end{array}$} \\
\hline$\tau$ & $\mathrm{x}$ & $\mathrm{y}$ & $\mathrm{z}$ & & \\
\hline 1.E-10 & -215.32731201862 & -1650.3697144277 & 1635.1626824928 & 1.99 & \\
\hline 1.E-11 & -215.32794605537 & -1650.3715299629 & 1635.1612149497 & 2.64 & \\
\hline 1.E-12 & -215.32799474610 & -1650.37166939046 & 1635.1611022567 & 3.49 & \\
\hline 1.E-13 & -215.32799868206 & -1650.3716806616 & 1635.1610931478 & 4.62 & \\
\hline 1.E-14 & -215.32799901817 & -1650.3716816241 & 1635.1610923701 & 6.15 & \\
\hline 1.E-10 & -215.32849813488 & -1650.3731189359 & 1635.1600219626 & 0.32 & 6.22 \\
\hline 1.E-11 & -215.32849812774 & -1650.3731189154 & 1635.1600219790 & 0.35 & 7.54 \\
\hline 1.E-12 & -215.32849812980 & -1650.3731189214 & 1635.1600219744 & 0.40 & 8.73 \\
\hline 1.E-13 & -215.32849813332 & -1650.3731189310 & 1635.1600219653 & 0.44 & 10.5 \\
\hline 1.E-14 & -215.32849813453 & -1650.3731189349 & 1635.1600219635 & 0.49 & 12.6 \\
\hline
\end{tabular}

Table 7 Results for Problem 6

\begin{tabular}{|c|c|c|c|c|c|}
\hline \multicolumn{4}{|c|}{ Spacecraft Position at End of Calculation } & \multirow{2}{*}{$\begin{array}{l}\text { CPU } \\
(\mathrm{sec})\end{array}$} & \multirow{2}{*}{$\begin{array}{l}\mathrm{CPU} \\
\text { ratio }\end{array}$} \\
\hline$\tau$ & $\mathrm{x}$ & $\mathrm{y}$ & $\mathrm{z}$ & & \\
\hline 1.E-10 & 21572817.105605 & -139377155.25969 & -62943596.519662 & 0.14 & \\
\hline 1.E-11 & 21572817.105556 & -139377155.25962 & -62943596.519125 & 0.15 & \\
\hline 1.E-12 & 21572817.105508 & -139377155.25961 & -62943596 & & \\
\hline 1.E-13 & 21572817.105509 & -139377155.25960 & -62943596.518999 & 0.25 & \\
\hline 1.E-14 & 21572817.105496 & -139377155.25961 & -62943596.518987 & 0.34 & \\
\hline 1.E-10 & 7 & -139 & -62943596 & 1 & \\
\hline 1.E-1 & 1572816.904606 & -139377156.15407 & -62943596 & 0.12 & \\
\hline 1.E-12 & 21572816.904607 & -139377156.15407 & 62943596. & 0.14 & .50 \\
\hline 1.E-13 & 1572816.904607 & -139377156.15407 & -62943596 & & \\
\hline 1.E-14 & 21572816.904607 & -139377156.15407 & -62943596.9802247 & 0.17 & 2.00 \\
\hline
\end{tabular}


Table 8 Results for Problem 7

\begin{tabular}{|c|c|c|c|c|c|}
\hline \multicolumn{4}{|c|}{ Spacecraft Position at End of Calculation } & \multirow{2}{*}{$\begin{array}{l}\mathrm{CPU} \\
(\mathrm{sec})\end{array}$} & \multirow{2}{*}{$\begin{array}{l}\mathrm{CPU} \\
\text { ratio }\end{array}$} \\
\hline$\tau$ & $\mathrm{x}$ & $\mathrm{y}$ & $\mathrm{z}$ & & \\
\hline I.E-10 & 174298859.53574 & 117412103.45296 & 49149031.016983 & 0.14 & \\
\hline 1.E-11 & 174298859.53061 & 117412103.45425 & 49149031.017954 & 0.15 & \\
\hline E-12 & 174298859.53010 & 117412103.45436 & 49149031.018040 & 0.17 & \\
\hline I.E- & 174298859.53005 & 117412103.45437 & 49149031.018048 & 0.18 & \\
\hline E-14 & 174298859.53003 & 117412103.45437 & 49149031.018052 & 0.23 & \\
\hline & 1.90 & 11741 & & 0.11 & \\
\hline 1.E-11 & 174298891.93452 & 117412111.58059 & 49149027.497159 & 0.13 & \\
\hline 1.E-12 & 174298891.93452 & 117412111.58059 & 49149027.497160 & 0.15 & \\
\hline 1.E-13 & 174298891.93453 & 117412111.58059 & 49149027.497159 & 0.17 & 1.06 \\
\hline 1.E- & 174298891.93453 & 117412111.58059 & 49149027.497159 & 0.17 & \\
\hline
\end{tabular}

Table 9 Results for Problem 8

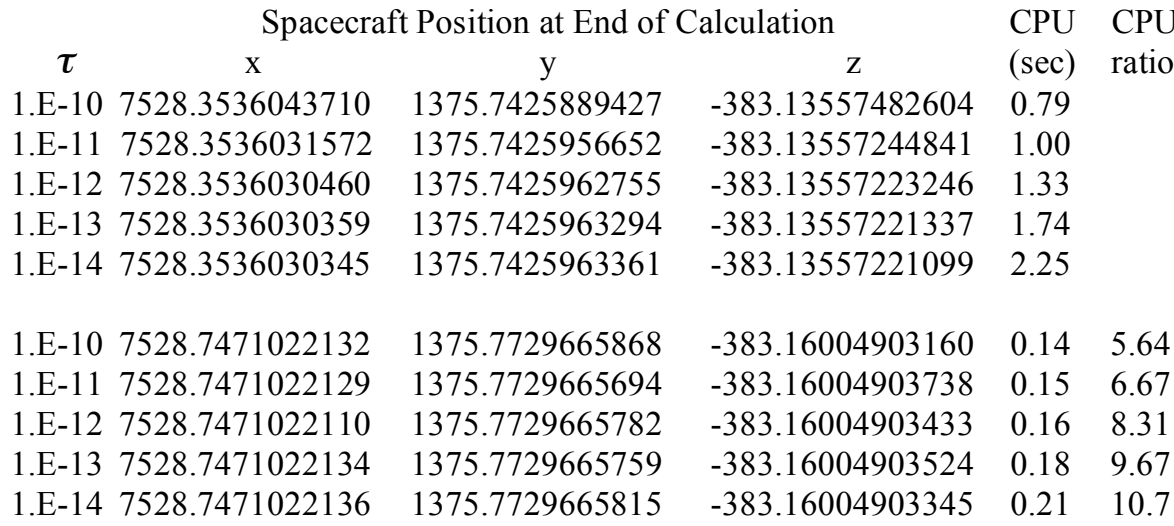

Table 10 Results for Problem 9

\begin{tabular}{cccccc}
\multicolumn{4}{c}{ Spacecraft Position at End of Calculation } & CPU & CPU \\
$\boldsymbol{\tau}$ & $\mathrm{x}$ & $\mathrm{y}$ & $\mathrm{z}$ & $(\mathrm{sec})$ & ratio \\
1.E-10 & -6179.7835988316 & 19484.717456953 & 11599.814016718 & 0.12 & \\
1.E-11 & -6179.7835986778 & 19484.717455196 & 11599.814015865 & 0.14 & \\
1.E-12 & -6179.7835986665 & 19484.717454928 & 11599.814015733 & 0.17 & \\
1.E-13 & -6179.7835986627 & 19484.717454902 & 11599.814015720 & 0.22 & \\
$1 . E-14$ & -6179.7835986621 & 19484.717454906 & 11599.814015723 & 0.27 & \\
& & & & & \\
1.E-10 & -6179.2994738523 & 19483.004328592 & 11598.975228083 & 0.04 & 3.00 \\
1.E-11 & -6179.2994738523 & 19483.004328592 & 11598.975228083 & 0.05 & 2.80 \\
1.E-12 & -6179.2994738525 & 19483.004328591 & 11598.975228082 & 0.05 & 3.40 \\
1.E-13 & -6179.2994738524 & 19483.004328591 & 11598.975228083 & 0.04 & 5.50 \\
1.E-14 & -6179.2994738522 & 19483.004328591 & 11598.975228083 & 0.05 & 5.40
\end{tabular}

Table 11 summarizes the CPU ratios. TS is faster than RKF by more than an order of magnitude in 18 of 45 cases. The average speedup is 15.8. For the interplanetary trajectory problems (4-9) the average speedup is 4.53 . The gain here is smaller due to the additional equations that TS must solve to account for other body motion. As noted previously, TS must integrate other body motion as part of the differential system, whereas RKF obtains other body motion from ephemeris files. This difference in the integration methods explains the small differences in spacecraft positions observed in Tables 2-10. 


\begin{tabular}{|c|c|c|c|c|c|c|c|c|c|}
\hline \multirow{2}{*}{$\tau$} & \multicolumn{3}{|c|}{ Table 11} & \multicolumn{4}{|c|}{ RKF/TS CPU ratios } & \multirow[b]{2}{*}{8} & \multirow[b]{2}{*}{9} \\
\hline & 1 & 2 & 3 & 4 & 5 & 6 & 7 & & \\
\hline 1.E-10 & 34.6 & 27.1 & 19.2 & 2.31 & 6.22 & 1.27 & 1.27 & 5.64 & 3.00 \\
\hline 1.E-11 & 41.4 & 31.6 & 22.6 & 2.55 & 7.54 & 1.25 & 1.15 & 6.67 & 2.80 \\
\hline 1.E-12 & 48.9 & 36.9 & 27.0 & 2.95 & 8.73 & 1.50 & 1.13 & 8.31 & 3.40 \\
\hline 1.E-13 & 57.3 & 43.4 & 31.2 & 3.55 & 10.5 & 1.56 & 1.06 & 9.67 & 5.50 \\
\hline 1.E-14 & 68.3 & 50.7 & 36.6 & 4.35 & 12.6 & 2.00 & 1.35 & 10.7 & 5.40 \\
\hline
\end{tabular}

Another important property to consider is convergence. Tables $12-20$ present the number of converged digits obtained for each spacecraft coordinate at each error tolerance, where the $\tau=10^{-14}$ case was used as the fully converged solution. RKF results are on top and TS on bottom. TS has more converged digits than RKF in 103 out of 108 cases, while RKF has more converged digits in one case. On average, TS has 2.63 more converged digits per case. The results also indicate that TS solutions are nearly fully converged at all error tolerances, suggesting that the step selection method may be too conservative. Finally, it should be noted that convergence itself does not necessarily imply accuracy. However, it does indicate that a necessary condition for accuracy is satisfied.

\begin{tabular}{cccc}
$\begin{array}{c}\text { Table } 12 \\
\text { of Converged }\end{array}$ & \multicolumn{3}{c}{$\begin{array}{c}\text { Number } \\
\text { fugits }\end{array}$} \\
for Problem $\mathbf{1}$ \\
$\begin{array}{cccc}\boldsymbol{\tau} & \mathrm{x} & \mathrm{y} & \mathrm{z} \\
1 . \mathrm{E}-10 & 6 & 6 & 6 \\
1 . \mathrm{E}-11 & 7 & 7 & 7 \\
1 . \mathrm{E}-12 & 8 & 8 & 8 \\
1 . \mathrm{E}-13 & 9 & 9 & 10 \\
& & & \\
1 . \mathrm{E}-10 & 10 & 11 & 11 \\
1 . \mathrm{E}-11 & 10 & 10 & 10 \\
1 . \mathrm{E}-12 & 11 & 11 & 11 \\
1 . \mathrm{E}-13 & 10 & 10 & 11\end{array}$
\end{tabular}

Table 16 Number of Converged Digits for Problem 5

\begin{tabular}{|c|c|c|c|c|c|}
\hline$\tau$ & $\mathrm{x}$ & $\mathrm{y}$ & $\mathrm{z}$ & $\tau$ & $\begin{array}{lll}x & y & z\end{array}$ \\
\hline 1.E-10 & 5 & 6 & 6 & 1.E-10 & $\begin{array}{lll}10 & 12 \quad 10\end{array}$ \\
\hline 1.E-11 & 6 & 7 & 7 & 1.E-11 & $\begin{array}{lll}10 & 13 & 11\end{array}$ \\
\hline 1.E-12 & 7 & 8 & 8 & 1.E-12 & 1014 \\
\hline 1.E-13 & 9 & 9 & 9 & 1.E-13 & 1213 \\
\hline 1.E-10 & 12 & 11 & 13 & 1.E-10 & 1414 \\
\hline 1.E-11 & 11 & 11 & 11 & 1.E-11 & 1314 \\
\hline 1.E-12 & 11 & 11 & 11 & 1.E-12 & $14 \quad 14$ \\
\hline 1.E-13 & 11 & 12 & 11 & 1.E-13 & $14 \quad 14$ \\
\hline
\end{tabular}

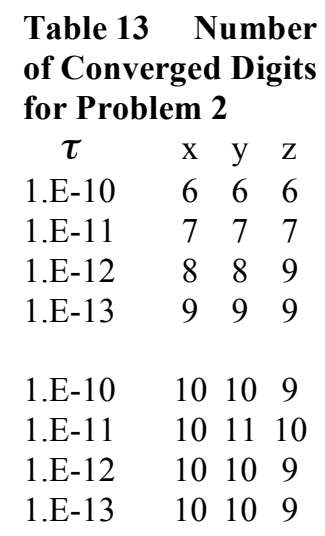

Table 17 Number of Converged Digits for Problem 6

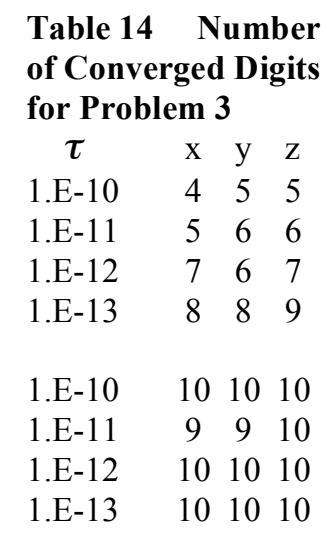

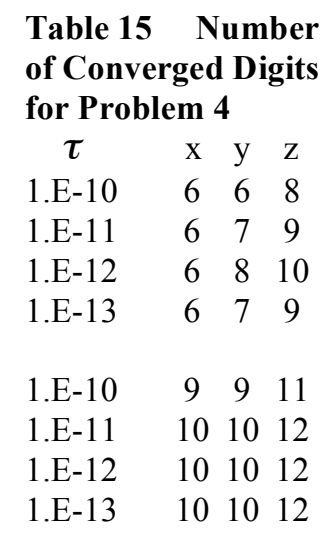

\begin{tabular}{|c|c|c|c|}
\hline \multicolumn{2}{|c|}{$\begin{array}{l}\text { Table } 18 \text { Number } \\
\text { of Converged Digits } \\
\text { for Problem } 7\end{array}$} & \multicolumn{2}{|c|}{$\begin{array}{l}\text { Table } 19 \text { Number } \\
\text { of Converged Digits } \\
\text { for Problem } 8\end{array}$} \\
\hline$\tau$ & $\begin{array}{lll}x \quad y \quad z\end{array}$ & $\tau$ & $\begin{array}{lll}x & y & z\end{array}$ \\
\hline 1.E-10 & 101110 & 1.E-10 & 98 \\
\hline 1.E & $\begin{array}{lll}11 & 12 & 11\end{array}$ & 1.E-11 & 1010 \\
\hline 1.E-12 & $\begin{array}{lll}12 & 13 & 11\end{array}$ & 1.E-12 & $\begin{array}{lll}11 & 11 & 10\end{array}$ \\
\hline 1.E-13 & $12 \quad 14 \quad 13$ & 1.E-13 & 11111 \\
\hline 1.E-10 & $13 \quad 14 \quad 13$ & 1.E-10 & $\begin{array}{lll}12 & 11 & 11\end{array}$ \\
\hline 1.E-11 & $\begin{array}{lll}13 & 14 & 14\end{array}$ & 1.E-11 & 12111 \\
\hline 1.E-1 & $\begin{array}{lll}13 & 14 & 13\end{array}$ & 1.E-12 & 12121 \\
\hline 1.E-13 & $14 \quad 14 \quad 14$ & 1.E-13 & 12121 \\
\hline
\end{tabular}




\section{Conclusion}

Taylor series integration was implemented in a high fidelity trajectory analysis code (SNAP) and compared with $8^{\text {th }}$ order Runge-Kutta Fehlberg on a representative set of trajectory problems. On average, TS was more than an order of magnitude faster than RKF. TS also showed superior convergence properties, having more converged digits than RKF in 103 out of 108 cases. Taylor series integration thus proved that it can provide rapid, highly accurate solutions to spacecraft trajectory problems. This is consistent with other reports which have found Taylor series integration to be superior to conventional methods in both speed and accuracy ${ }^{11,16,20}$.

\begin{tabular}{cccc}
$\begin{array}{c}\text { Table } 20 \\
\text { of Converged }\end{array}$ & \multicolumn{3}{c}{$\begin{array}{c}\text { Number } \\
\text { Digits }\end{array}$} \\
for Problem \\
$\begin{array}{cccc}\boldsymbol{\tau} & \mathrm{x} & \mathrm{y} & \mathrm{z} \\
1 . \mathrm{z}-10 & 10 & 9 & 10 \\
1 . \mathrm{E}-11 & 11 & 11 & 11 \\
1 . \mathrm{E}-12 & 11 & 12 & 12 \\
1 . \mathrm{E}-13 & 12 & 12 & 13 \\
& & & \\
\text { 1.E-10 } & 13 & 13 & 14 \\
\text { 1.E-11 } & 13 & 13 & 14 \\
\text { 1.E-12 } & 12 & 14 & 13 \\
\text { 1.E-13 } & 13 & 14 & 14\end{array}$
\end{tabular}

\section{References}

${ }^{1}$ Collatz, L., The Numerical Treatment of Differential Equations, $3^{\text {rd }}$ ed., Springer, Berlin, 1960.

${ }^{2}$ Steffensen, J.F., "On the Restricted Problem of Three Bodies," Kong. Danske. Videnskab. Selskab. Mat-Fys. Med., Vol. 30, 1956.

${ }^{3}$ Deprit, A. and Price, J., "The Computation of Characteristic Exponents in the Planar Restricted Problem of Three Bodies," Astronom. J., Vol. 70, 1965, p. 836.

${ }^{4}$ Deprit, A. and Zahar, R.V.M., "Numerical Integration of an Orbit and its Concomitant Variations by Recurrent Power Series," ZAMP, Vol. 17, 1966, p. 425.

${ }^{5}$ Miller, J.C.P., "The Numerical Solution of Ordinary Differential Equations" in Numerical Analysis, An Introduction (J. Walsh, ed.), Chapter 4, Academic Press, New York and London, 1966.

${ }^{6}$ Gibbons, A., "A Program for the Automatic Integration of Differential Equations Using the Method of Taylor Series," Comput. J, Vol. 3, 1960, p. 108.

${ }^{7}$ Moore, R.A., Interval Analysis, Prentice-Hall, Englewood Cliffs, NJ, 1966.

${ }^{8}$ Leavitt, J.A., "Methods and Applications of Power Series," Math. Comp., Vol. 20, 1966, p. 46.

${ }^{9}$ Nikolaev, V.S., "The Solution of Systems of Ordinary Differential Equations by Expansion in Power Series on High Speed Computers," USSR Comp. Math. And Math. Phys., Vol. 5, 1965, p. 32.

${ }^{10}$ Barton, D., Willers, I.M. and Zahar, R.V.M., "The Automatic Solution of Ordinary Differential Equations by the Method of Taylor Series," Comput. J., Vol. 14, 1971, p. 243.

${ }^{11}$ Barton, D., Willers, I.M. and Zahar, R.V.M., "Taylor Series Methods for Ordinary Differential Equations - an

Evaluation," in Mathematical Software, John Rice (Ed.), Academic Press, New York, 1971, p. 369.

${ }^{12}$ Norman, A.C., "Expanding the Solutions of Implicit Sets of Ordinary Differential Equations in Power Series, Comput. J., Vol. 19, 1976, p. 63.

${ }^{13}$ Kedem, G., "Automatic Differentiation of Computer Programs," A.C.M. Trans. Math. Softw., Vol. 6, 1980, p. 150.

${ }^{14}$ Rall, L.B., "Automatic Differentiation: Techniques and Applications," in Lecture Notes in Computer Science, Vol. 120, Springer-Verlag, New York, 1981.

${ }^{15}$ Chang, Y.F., "Automatic Solution of Differential Equations," in Constructive and Computational Methods for Differential and Integral Equations, D.L. Colton and R.P. Gilbert (eds.), Lecture Notes in Mathematics, Vol. 430, Springer-Verlag, New York, 1974, p. 61.

${ }^{16}$ Corliss, G. and Chang, Y.F., "Solving Ordinary Differential Equations Using Taylor Series," A.C.M. Trans. Math. Softw., Vol. 8, 1982, p. 114

${ }^{17}$ Chang, Y.F., Corliss, G. and Morris, R., ATSMCC User Manual, Dep. of Mathematics, Statistics, and Computer Science Rep., Marquette Univ., Marquette, WI, 1979.

${ }^{18}$ Chang, Y.F. and Corliss, G., "Compiler for the Solution of Ordinary Differential Equations Using Taylor Series," Tech. Rep., Marquette Univ., Marquette, WI, 1981.

${ }^{19}$ Savageau, M.A. and Voit, E.O., "Recasting Nonlinear Differential Equations as S-Systems: a Canonical Nonlinear Form," Mathematical Biosciences, Vol. 87, 1987, p. 83.

${ }^{20}$ Irvine, D.H. and Savageau, M.A., "Efficient Solution of Nonlinear Ordinary Differential Equations Expressed in S-System Canonical Form," SIAM J. Numer. Anal., Vol. 27, 1990, p. 704. 
${ }^{21}$ Stanford, R.H., Berryman, K.W. and Breckheimer, P.J., “Application of Taylor's Series to Trajectory Propagation,” AIAA Paper 86-2166, AIAA/AAS Astrodynamics Conference, 1986.

${ }^{22}$ Berryman, K.W., Stanford, R.H and Breckheimer, P.J., "The ATOMFT Integrator: Using Taylor Series to Solve Ordinary Differential Equations," AIAA Paper 88-4217-CP, AIAA/AAS Astrodynamics Conference, 1988.

${ }^{23}$ Gofen, A., "The Modern Taylor Method Package," URL, http://www.ski.org/Rehab/MacKeben/gofen/TaylorMethod.htm

${ }^{24}$ Gofen, A., "Interactive Environment for the Taylor integration (in 3D Stereo)," Proceedings of the 2005 International Conference on Scientific Computing CSC'05, 2005.

${ }^{25}$ Scott, J.R., "Solving ODE Initial Value Problems With Implicit Taylor Series Methods," NASA TM 2000-209400, 2000.

${ }^{26}$ Martini, M., "S.N.A.P. 2.3 User's Manual,” Analex Corporation, Glenn Research Center, Cleveland, OH, 2005.

${ }^{27}$ Fehlberg, E., "Classical Fifth-, Sixth-, Seventh-, and Eighth-Order Runge-Kutta Formulas with Stepsize Control," NASA TR R-287, October, 1968.

${ }^{28}$ Hairer, E., Norsett, S.P. and Wanner, G., Solving Ordinary Differential Equations I, $2^{\text {nd }}$ ed., Springer Series in Computational Mathematics, Springer-Verlag, New York, 1987, p. 168.

${ }^{29}$ Corliss, G. and Lowery, D., "Choosing a stepsize for Taylor series methods for solving ODE's,"J.Comp. and Applied Math., Vol. 3, No. 4, 1977, p. 251. 


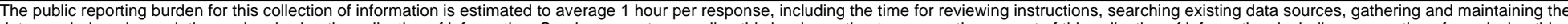

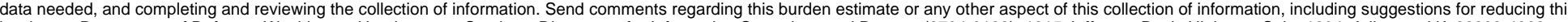

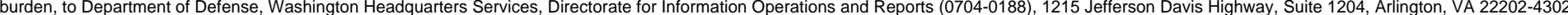

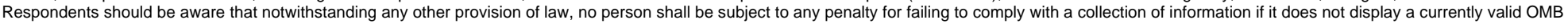
control number.

COntrol number.

\section{REPORT DATE (DD-MM- $Y Y Y Y)$ \\ 2. REPORT TYPE \\ 3. DATES COVERED (From - To)}

01-08-2008

\section{TITLE AND SUBTITLE}

Technical Memorandum

High Speed Solution of Spacecraft Trajectory Problems Using Taylor Series Integration

5b. GRANT NUMBER

5c. PROGRAM ELEMENT NUMBER

6. AUTHOR(S)

Scott, James, R.; Martini, Michael, C.

\section{5d. PROJECT NUMBER}

5e. TASK NUMBER

5f. WORK UNIT NUMBER

WBS 526282.01.03.01.02.01.06

8. PERFORMING ORGANIZATION REPORT NUMBER

E-16609

National Aeronautics and Space Administration

John H. Glenn Research Center at Lewis Field

Cleveland, Ohio 44135-3191

9. SPONSORING/MONITORING AGENCY NAME(S) AND ADDRESS(ES)

National Aeronautics and Space Administration

Washington, DC 20546-0001

\section{SPONSORING/MONITORS ACRONYM(S) \\ NASA}

\section{SPONSORING/MONITORING} REPORT NUMBER

NASA/TM-2008-215439

\section{DISTRIBUTIONIAVAILABILITY STATEMENT}

Unclassified-Unlimited

Subject Categories: 13 and 64

Available electronically at http://gltrs.grc.nasa.gov

This publication is available from the NASA Center for AeroSpace Information, 301-621-0390

\section{SUPPLEMENTARY NOTES}

\section{ABSTRACT}

Taylor series integration is implemented in a spacecraft trajectory analysis code - the Spacecraft N-body Analysis Program (SNAP) - and compared with the code's existing eighth-order Runge-Kutta Fehlberg time integration scheme. Nine trajectory problems, including near Earth, lunar, Mars and Europa missions, are analyzed. Head-to-head comparison at five different error tolerances shows that, on average, Taylor series is faster than Runge-Kutta Fehlberg by a factor of 15.8. Results further show that Taylor series has superior convergence properties. Taylor series integration proves that it can provide rapid, highly accurate solutions to spacecraft trajectory problems.

\section{SUBJECT TERMS}

Taylor series; Spacecraft trajectory; Runge-Kutta method; Trajectory analysis; SNAP; Numerical integration; High order

\section{SECURITY CLASSIFICATION OF:}

a. REPORT

$\mathrm{U}$

b. ABSTRACT

U
17. LIMITATION OF ABSTRACT

UU
18. NUMBER

OF

PAGES

21 19a. NAME OF RESPONSIBLE PERSON

STI Help Desk (email:help@sti.nasa.gov)

19b. TELEPHONE NUMBER (include area code) 301-621-0390 

